\title{
Manufacture Errors Analysis and Control of Cable Dome
}

\author{
Jianhua Zhang ${ }^{1, *}$, Ke Sun $^{2}$ and Zhenqing Wang ${ }^{1}$ \\ ${ }^{1}$ College of Aerospace and Civil Engineering, Harbin Engineering University, Harbin, 150001, China \\ ${ }^{2}$ College of Shipbuilding Engineering, Harbin Engineering University, Harbin, 150001, China
}

\begin{abstract}
Applying prestress is the key technique of the cable dome. However, it is difficult to ensure that designed prestress of cables have been exactly applied to the structure in the site due to the fact that various kinds of errors will be introduced during construction. Thus it is necessary to present an effective method to guide construction to avoid construction team regulate the real prestress of cables repeatedly. In the paper, sensitivity analysis method based on spearman rank-order correlation is presented and the random errors are simulated by Monte Carlo method to solve the manufacture error. The sensitivity of effect of bearing and cable length manufacture errors on structural performance is analyzed in a numerical model of cable dome with the diameter of $62 \mathrm{~m}$. A cable dome model with diameter of $6 \mathrm{~m}$ is designed and experimented. The experiential results are mostly consistent with the theoretical ones, which prove that the analysis theory is correct and the control method is effective. At last, some suggestions are made for manufacture errors of cable dome.
\end{abstract}

Keywords: Cable dome, sensitivity analysis, spearman rank-order correlation, manufacture errors.

\section{INTRODUCTION}

Cable dome, proposed by Geiger after extending Fuller's ideas of tensegrity $[1,2]$, is a kind of prestressed space structure. Cable dome system composed of continuous prestressed cables and individual compression struts is a selfequilibrium system. The successful applications of cable dome in designing in the circular roof structures of the Gymnastics Arena (diameter $119.8 \mathrm{~m}$ ) and the Fencing Arena (diameter $89.9 \mathrm{~m}$ ) constructed for Seoul Olympics in 1988 [3]. From then, several projects have been built in the world such as the Suncoast Dome (circular plan, diameter $210 \mathrm{~m}$ ) built in St. Petersburg, the Red bird Arena with the first elliptical plan (diameter of the long axis is 91.4 and short axis is $76.8 \mathrm{~m}$ ), which was built in Illinois State University. Georgia Dome [4] (elliptical plan, diameter of the long axis and short axis is 240.79and $192.02 \mathrm{~m}$ respectively) was designed for the Atlanta Olympic Games in 1996. As an innovative, light structure system, cable dome attracts a lot of attention from engineers and wildly used in large span structures.

Cable dome is different from other traditional structures that its stiffness comes from introduced prestress during construction other than obtains from the geometry and material. The stiffness and shape of the cable dome structure is correlative with the prestress distribution induced. Therefore, it is the key issue to control the force of cables and induce designed value of prestress to the structure accurately. In practical constructions, however, it is difficult to ensure no difference between the real prestress

*Address correspondece to this author at the College of Aerospace and Civil Engineering, Harbin Engineering University, Harbin, 150001, China;

Tel: +86-451-82519201; Fax: +86-451-82519210;

E-mails: jhzhang1980@hotmail.com,zjh@hrbeu.edu.cn distribution and the designed value due to existed construction errors. The mechanical problems which considering the prestressing of tendons in turn encountered during the construction had been solved theoretically [5-8]. In fact, there is still a great difference between the real prestress and the designed value due to existing construction errors. Therefore, it is necessary to study how to control construction errors effectively.

The objective of this paper is to study the sensitivity of bars regulated on structural behaviors to determine the feasible bar to improve construction efficiency and maximum allowable manufacture errors. The basic sensitivity analysis theory is firstly presented in details, then sensitivity of manufacture errors in different cases on structural behaviors is analyzed and maximum allowable errors limits are presented. In the following, an experimental modal is designed and tested. At last, some suggestions on construction errors are given out, which provide a reference for cable dome design and construction.

\section{SENSITIVITY ANALYSIS METHOD BASED ON SPEARMAN RANK-ORDER CORRELATION}

Spearman rank-order correlation method is used to test non-parametric statistical correlation [9]. A sample $x_{1}, x_{2}, \ldots$, $x_{n}$, the sample elements are arranged in ascending order $x_{(1)}$, $x_{(2)}, \ldots, x_{(\mathrm{n})}$, if $x_{\mathrm{i}}=x_{(\mathrm{Ri})}$, that is, the rank of $x_{\mathrm{i}}(\mathrm{i}=1,2, \ldots, \mathrm{n})$ is $R_{i},\left(R_{i}=1,2, \ldots, \mathrm{n}\right)$ in the sample $x_{1}, x_{2}, \ldots, x_{n}$. It can be seen from the definition of rank, the rank $R_{i}$ is the order of the entire sample sequence from small to large.

For the data $\left(\begin{array}{l}x_{1} \\ y_{1}\end{array}\right),\left(\begin{array}{l}x_{2} \\ y_{2}\end{array}\right) \ldots\left(\begin{array}{l}x_{n} \\ y_{n}\end{array}\right)$, the Spearman rank correlation coefficient is calculated as follows: the rank of 
$x_{\mathrm{i}}$ in $x_{1}, x_{2}, \ldots, x_{n}$ is $R_{i}$, and the rank $y_{i}$ in $y_{1}, y_{2}, \ldots, y_{\mathrm{n}}$ is $Q_{i}$ $(i=1,2, \ldots, \mathrm{n})$. Construct a new data with $R_{i}$ and $Q_{i}$ instead of $x_{i}$ and $y_{i}$ respectively, the Spearman rank correlation coefficient of the original data is

$$
\begin{aligned}
& r_{s}=\frac{\sum_{i=1}^{n}\left(R_{i}-\bar{R}\right)\left(Q_{i}-\bar{Q}\right)}{\sqrt{\sum_{i=1}^{n}\left(R_{i}-\bar{R}\right)^{2}} \sqrt{\sum_{i=1}^{n}\left(Q_{i}-\bar{Q}\right)^{2}}} \\
& \text { Where, } \quad \bar{R}=\frac{\sum_{i=1}^{n} R_{i}}{n}=\frac{n+1}{2}, \bar{Q}=\frac{\sum_{i=1}^{n} Q_{i}}{n}=\frac{n+1}{2} . \quad \text { The rank }
\end{aligned}
$$

correlation coefficient range from- 1 to1, when two variables monotonically increase, the correlation coefficient is positive (+1.0 means perfect positive correlation); when two variables monotonically decrease, the correlation coefficient is negative (-1.0 means perfect negative correlation); when there is no relationship between the two variables, the relevant coefficient is zero. The greater is absolute value, the greater is the correlation between two variables.

In the sensitivity analysis, structural response is named $y$, and construction errors named $x$. Construction errors are simulated by Monte Carlo method. $r_{s}$ denotes correlation between structural responses to parameters. Sensitivity of construction errors to structural performance is the

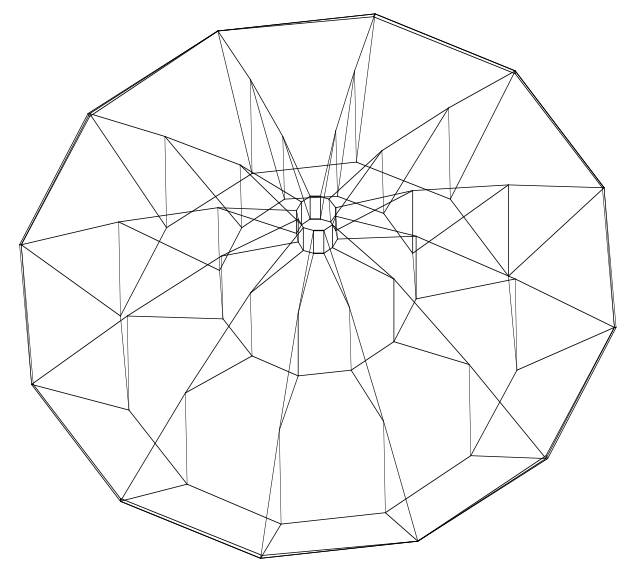

Fig. (1). Perspective of cable dome. correlation coefficient between errors parameters and structural behaviors. Therefore, the sensitivity analysis can be carried out by judging the correlation of construction errors. If the error parameter is highly correlative with the structural performance, the effect is significant. Therefore, the parameter should be controlled strictly in the practical construction.

\section{SENSITIVITY ANALYSIS OF MANUFACTURE ERRORS}

Errors generated in construction process are random. Generally, manufacture errors should conform to normal distribution [10]. Cables length and bearing manufacture errors are assumed to subject to normal distribution. Sample size is $2000, R_{a}$ denotes allowable manufacture errors and $\delta$ denotes manufacture control accuracy, according to actual construction, $\delta$ takes $5 \%$. The actual manufacture error range $R_{e}$ is

$R_{e}=\left[(1-\delta) R_{a},(1+\delta) R_{a}\right]$

\section{Structural Model}

The structural model employed is shown in Figs. (1-3), it is noticed from Fig. (1) that the network use the quadrangled geometry. The numbers of supports are shown in Fig. (2). Fig. (3) displays the layout and dimension of the cable dome, the span and the rise of the dome are $62 \mathrm{~m}$ and $9.3 \mathrm{~m}$ respectively. In Fig. (3), letter RC1, RC2 and RC3 denote the

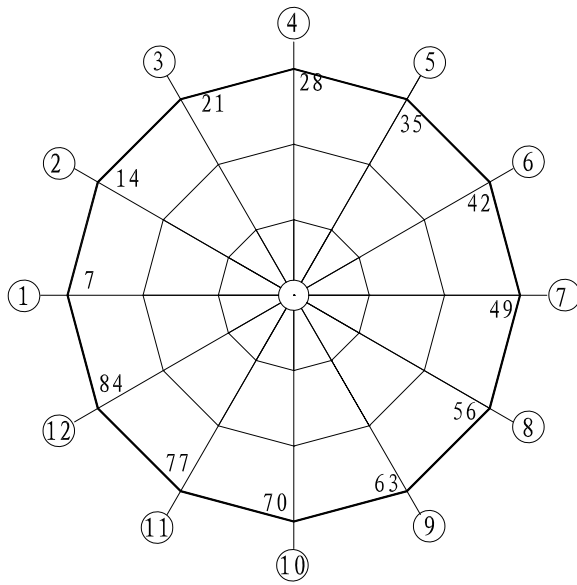

Fig. (2). Bearing number of cable dome.

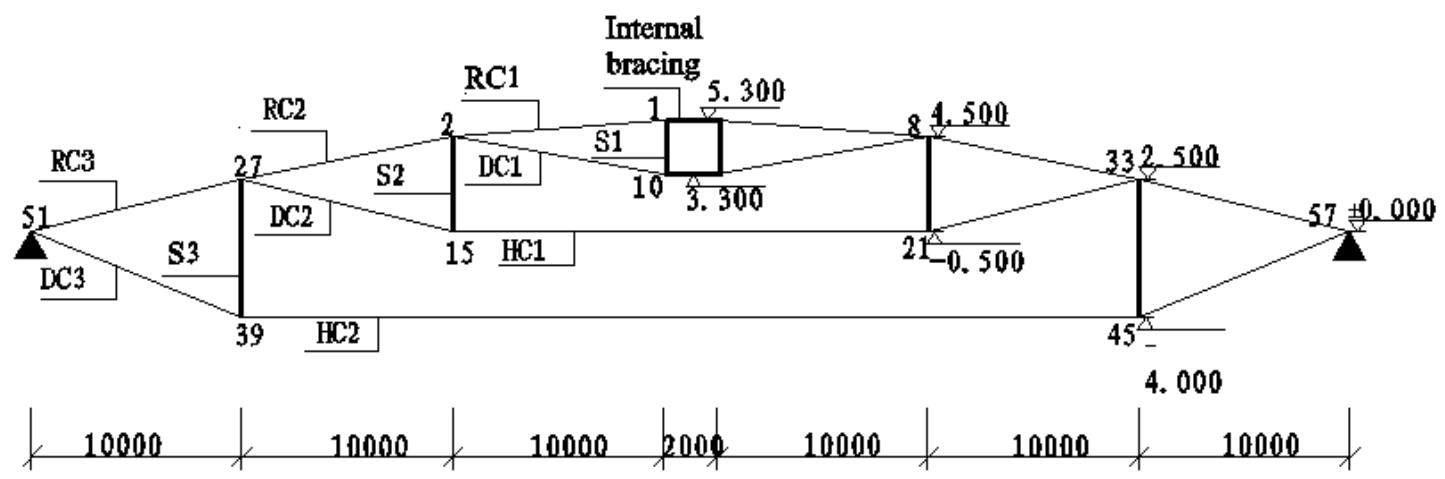

Fig. (3). Section of axis 1-7. 
ridge cable from outer layer to inner layer; DC1, DC2 and DC3 denote the diagonal cable, $\mathrm{HC} 1$ and $\mathrm{HC} 2$ denote the hoop cable, while S1, S2 and S3 denote the compression strut. The initial presstress distribution and cross section area are given in Table $\mathbf{1}$.

\section{Sensitivity Analysis of Bearing Manufacture Errors}

Bearing manufacture errors $R x, R y$ and $R z$ in radial, tangential and vertical direction respectively are taken as the input variables, and internal force of elements and nodal displacements in the axis 1-7 are taken as output variables.

In practical engineering, manufacture errors in all direction may produce in all bearing. Referring to "Technical Specification for Latticed Shells" (Section 6.7) [11], 7 cases (shown in Table 2) are considered including different random manufacture errors in different direction. Change ratio of internal force and nodal displacement are shown in Tables $\mathbf{3}$ and $\mathbf{4}$.

Table1. Initial Prestress Distribution and Cross Section Areas of Elements for Cable Dome

\begin{tabular}{|l|c|c|c|c|c|c|}
\hline & RC1 & RC2 & RC3 & DC1 & DC2 & DC3 \\
\hline \hline Initial prestress $(\mathrm{kN})$ & 155.23 & 256.35 & 428.07 & 97.51 & 178.63 & 287.99 \\
\hline Area $\left(\mathrm{mm}^{2}\right)$ & 731 & 731 & 1193 & 269 & 500 & 731 \\
\hline & $\mathrm{HC1}$ & $\mathrm{HC} 2$ & $\mathrm{~S} 1$ & $\mathrm{~S} 2$ & $\mathrm{~S} 3$ & -106.98 \\
\hline Initial prestress $(\mathrm{kN})$ & 329.99 & 516.68 & -11.61 & -51.35 & 2748.9 & \\
\hline Area $\left(\mathrm{mm}^{2}\right)$ & 731 & 1424 & 829.4 & 2120.6 & \\
\hline
\end{tabular}

Table 2. Cases of Bearing Manufacture Errors Considered

\begin{tabular}{|c|c|c|c|c|}
\hline Case & Mean of $R x(\mathbf{m m})$ & Mean of $R y(\mathrm{~mm})$ & Mean of $R z(\mathbf{m m})$ & $\delta$ \\
\hline 1 & 10 & 10 & 10 & $5 \%$ \\
\hline 2 & 20 & 20 & 20 & $5 \%$ \\
\hline 3 & 30 & 30 & 30 & $5 \%$ \\
\hline 4 & 20 & 10 & 10 & $5 \%$ \\
\hline 5 & 10 & 20 & 10 & $5 \%$ \\
\hline 6 & 10 & 10 & 20 & $5 \%$ \\
\hline 7 & 10 & 20 & 30 & $5 \%$ \\
\hline
\end{tabular}

Table 3. Change Ratio of Internal Force in 7 Cases of Manufacture Errors (\%)

\begin{tabular}{|l|c|c|c|c|c|c|c|}
\hline & Case1 & Case 2 & Case 3 & Case 4 & Case 5 & Case 6 & Case 7 \\
\hline \hline RC1 & 7.95 & 8.26 & 10.25 & 8.31 & 4.27 & 11.64 \\
\hline DC1 & 0.54 & 0.95 & 0.45 & 1.02 & 0.02 & 0.73 & 0.31 \\
\hline RC2 & 5.24 & 5.34 & 6.33 & 5.40 & 2.57 & 5.04 & 7.10 \\
\hline DC2 & -0.67 & -0.27 & -0.48 & -0.22 & -1.39 & -0.50 & -0.61 \\
\hline RC 3 & 2.79 & 3.03 & 3.51 & 3.08 & 0.93 & 2.74 & 3.91 \\
\hline DC3 & -3.36 & -2.96 & -3.14 & -2.91 & -4.04 & -3.20 & -3.30 \\
\hline HC1 & -0.66 & -0.24 & -0.51 & -0.20 & -1.28 & -0.46 & -0.71 \\
\hline HC2 & -3.34 & -2.93 & -3.20 & -2.89 & -3.96 & -3.15 & -3.40 \\
\hline S1 & 3.49 & 3.90 & 4.55 & 3.82 & 2.09 & 3.72 & 4.35 \\
\hline S2 & 1.12 & 1.35 & 1.56 & 1.44 & -0.50 & 1.06 & 1.97 \\
\hline S3 & -1.47 & -1.12 & -1.24 & -1.07 & -2.41 & -1.35 & -1.25 \\
\hline
\end{tabular}


It can be seen from the Table $\mathbf{3}$, the effect of manufacture errors on internal force of $\mathrm{RC} 1$ is most significant and then is the effect on RC2, 3 and DC3, but the effect on HC1, DC 1 and DC 2 is not significant. Compared with case 1 and 4 , the effect on internal force increase with the increase of $R x$, Compared with case 1 and 5 , the effect on internal force decrease with the increase of $R y$. From case 1 and 6 , it can be seen that the effect on internal force is not significant with the increase of $R z$. The nodal displacement increases with the increase of manufacture errors as shown in Table 4.

In summary, the effects are not great on structural performance of bearing manufacture errors. Maximum change ratio of internal force is $11.6 \%$ and maximum nodal displacement is $29.49 \mathrm{~mm}$ (less than $1 / 2000$ of span) when $R x$, $R y, R z$ take the value in Case 7 . The effect of radial manufacture error $R x$ is most apparent. Therefore, the radial manufacture errors should be controlled strictly. It is advised to control within $1 / 2000$ of distance between adjacent supports for the span within $60 \mathrm{~m}$.

\section{Sensitivity Analysis of Cable Length Manufacture Errors}

5 cases are considered including different random cable length manufacture errors. Mean of maximum cable length manufacture error are $0.05 \%, 0.10 \%, 0.15 \%, 0.20 \%$ and $0.25 \%$ of cable length respectively in case 1 to $5, \delta$ is $5 \%$. Change ratio of internal force and nodal displacement are shown in the Table $\mathbf{5}$.
From Table 5, the effect of cable length manufacture errors on structural performance are significant. Take case 1 as an example, if the maximum cable manufactures error is $0.05 \%$ of cable length, the internal force of RC 1 will change $36 \%$. Therefore, cable length manufacture should be controlled strictly. However, it is not appropriate or economical that manufacture errors of every cable are limited to the same value in practical construction, so it is necessary to carry out sensitivity analysis of manufacture errors for cable length in various positions on structural behaviors. The numerical results are shown in Figs. (4-7).

It can be seen that the sensitivity of manufacture errors in $\mathrm{HC} 2$ to internal force are most significant, that is from $45 \%$ to $67 \%$, followed by $\mathrm{RC} 3, \mathrm{DC} 3$ and $\mathrm{HC} 1$. While sensitivity of manufacture errors $\mathrm{RC} 1$ and $\mathrm{DC} 1$ and struts are not significant. Therefore, manufacture errors in $\mathrm{HC} 2, \mathrm{RC} 3$, DC3 and HC1 should be strictly controlled in practical engineering. For a cable with length of 10 to $30 \mathrm{~m}$, the maximum errors of $\mathrm{HC} 2, \mathrm{RC} 3, \mathrm{DC} 3$ and $\mathrm{HC} 1$ are advised to control to $0.05 \%$ of cable length, $\mathrm{RC} 2$ and $\mathrm{DC} 2$ are controlled to $0.10 \%$, and $\mathrm{RC} 1$ and $\mathrm{DC} 1$ controlled to $0.15 \%$ referring to domestic cable manufacture industry specifications.

\section{SUGGESTIONS ON CONSTRUCTION}

In practical construction, there are manufactures errors in bearing and bars, which may bring great deviation between

Table 4. Nodal Displacement in Construction Errors of 7 Cases(mm)

\begin{tabular}{|c|c|c|c|c|c|c|c|}
\hline Node & Case1 & Case 2 & Case 3 & Case 4 & Case 5 & Case 6 & Case 7 \\
\hline \hline 1 & 7.95 & 8.26 & 10.25 & 8.31 & 4.27 & 7.90 & 11.64 \\
\hline 2 & 0.54 & 0.95 & 0.45 & 1.02 & 0.02 & 0.73 & 0.31 \\
\hline 27 & 5.24 & 5.34 & 6.33 & 5.40 & 2.57 & 5.04 \\
\hline
\end{tabular}

Table 5. Change Ratio of Internal Force in 5 Cases of Cable Length Manufacture Errors (\%)

\begin{tabular}{|c|c|c|c|c|c|}
\hline $\mathrm{RC} 1$ & 36.33 & 62.63 & 89.07 & 123.73 & 150.51 \\
\hline $\mathrm{RC} 2$ & 31.47 & 56.49 & 81.14 & 112.47 & 136.40 \\
\hline DC 2 & 23.76 & 46.71 & 69.19 & 96.46 & 119.36 \\
\hline DC 3 & 20.60 & 43.13 & 65.16 & 92.89 & 115.39 \\
\hline $\mathrm{HC} 1$ & 23.77 & 46.73 & 69.21 & 96.48 & 119.39 \\
\hline $\mathrm{HC} 2$ & 20.61 & 43.14 & 65.17 & 92.89 & 115.41 \\
\hline
\end{tabular}




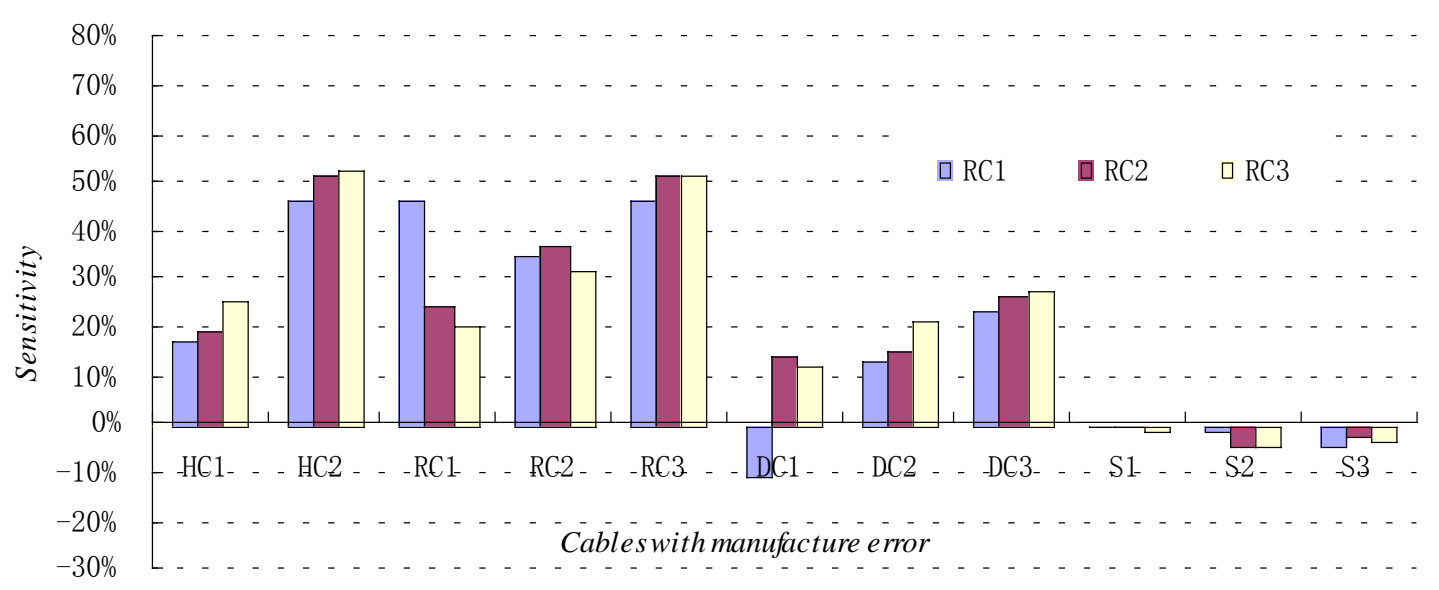

Fig. (4). Sensitivity of cable length manufacture errors to internal force of ridge cable.

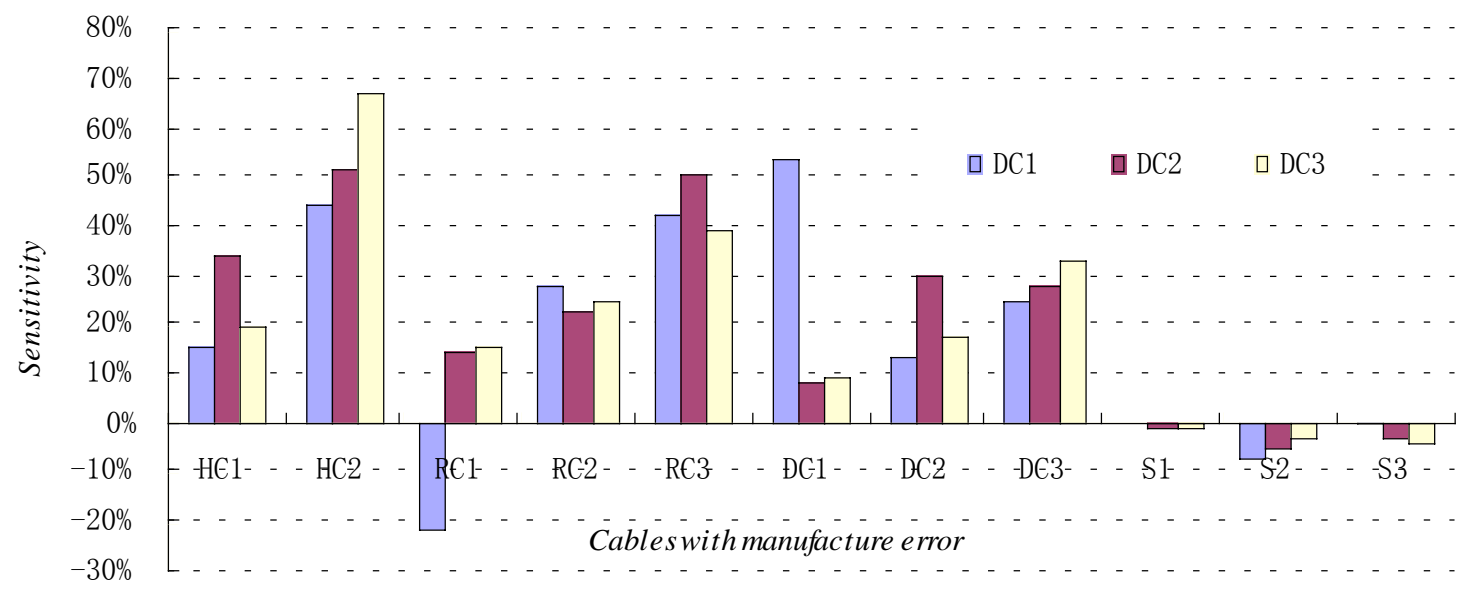

Fig. (5). Sensitivity of cable length manufacture errors to internal force of diagonal cables.

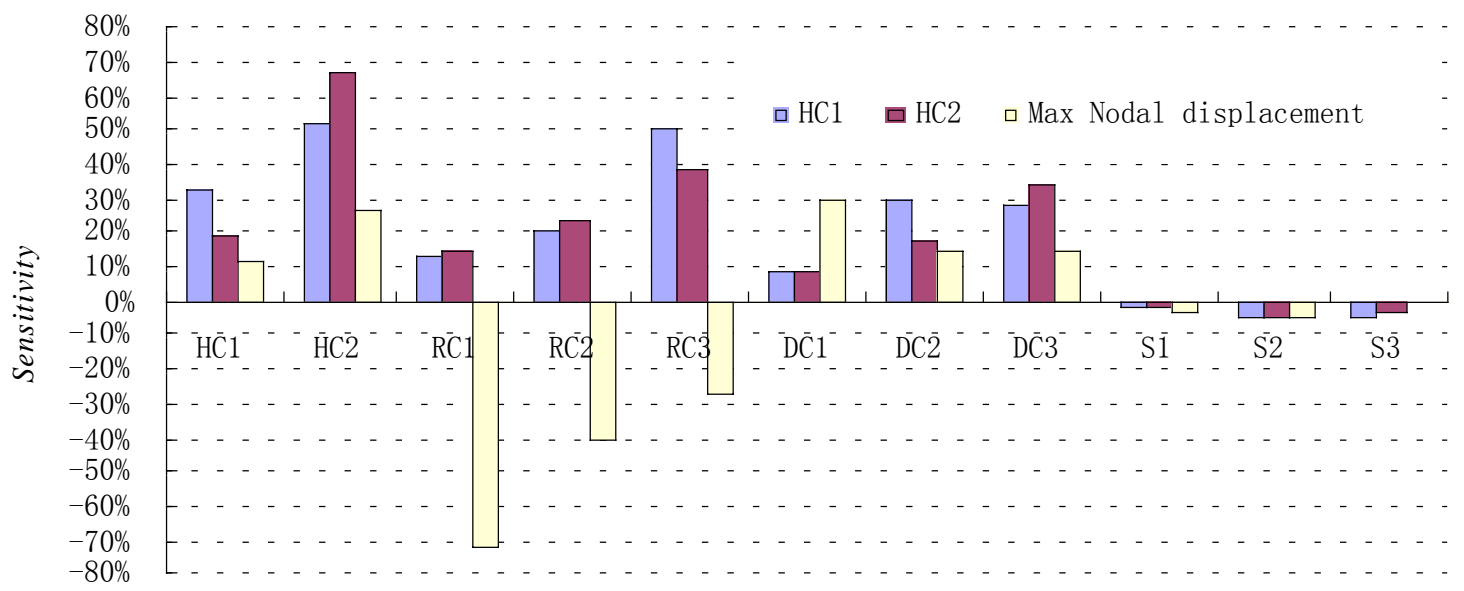

Cables with manufacture error

Fig. (6). Sensitivity of cable length manufacture errors to internal force of hoop cables and maximum nodal displacement.

actual internal force and design values after forming. Therefore, it needs a clear guideline to regulate errors effectively.

From the construction errors analysis in above section, we know that components with significant sensitivity have apparent effect on internal force and therefore should be controlled strictly. To the extent, if those components could be regulated, the construction efficiency would be improved. In theory, adjusting the bearing position can eliminate errors, but the actual location of bearings is generally fixed. It is not feasible to regulate bearing positions, but it is to regulate bars length in practical engineering. 


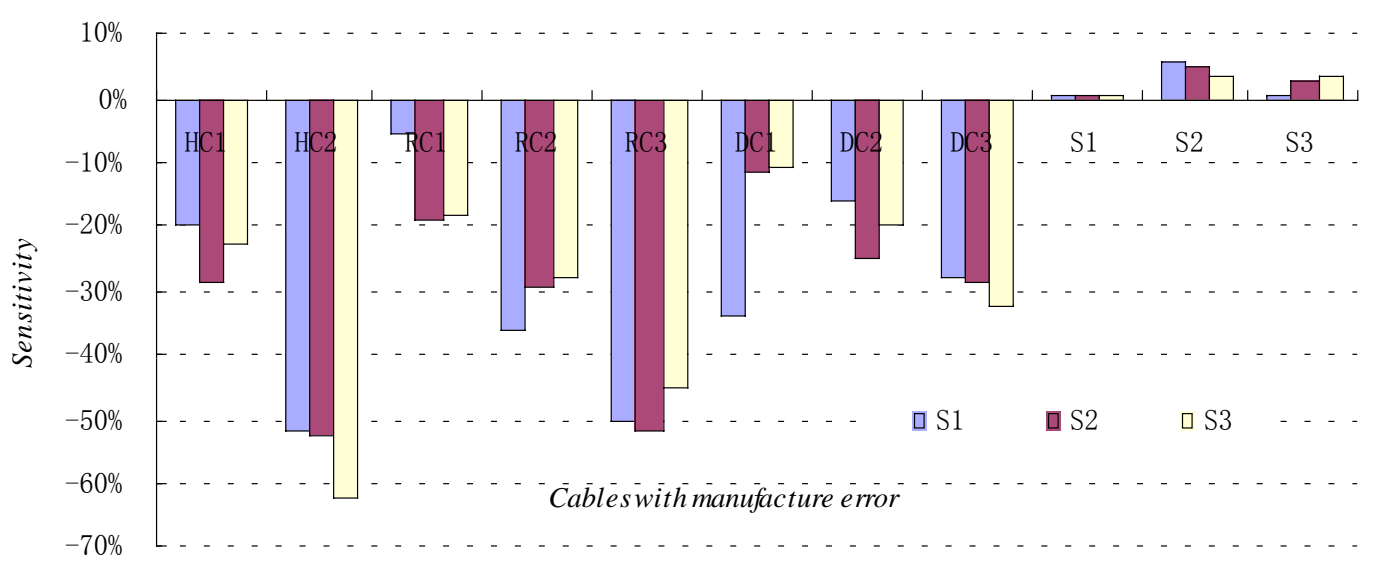

Fig. (7). Sensitivity of cable length manufacture errors to internal force of struts.

The paper present regulated bars in priority sequences, as shown in Table 6, the symbol (-) indicates that the force of regulated bars monotonically decrease with the member forces of the first row in table. For example, in practical construction, it is found that the internal force of $\mathrm{RC} 1$ is smaller than the design value, so we could increase this value by increasing internal force of $\mathrm{RC} 3, \mathrm{RC} 1, \mathrm{HC} 2, \mathrm{RC} 2$, $\mathrm{XC} 3, \mathrm{HC} 1, \mathrm{DC} 2$ and decreasing internal force of DC1, S3, $\mathrm{S} 2$ and S1. However, the most effective way is to regulate $\mathrm{RC} 3$ length, that is to say, shortening the RC3 length can significantly increase the RC1 internal force. From the priority sequences, it is not effective to regulate $\mathrm{S} 1$ length, because lengthening the DC1 length will not be great to change magnitude of $\mathrm{RC} 1$ internal force.

Considering top four bars in Table 6 are the most sensitive to internal forces, it is suggested to regulate those bar length in accordance with the priorities listed in the control group in the practical construction, which can improve the accuracy and efficiency of construction.

\section{EXPERIMENTS}

An experimental model with diameter $6 \mathrm{~m}$ (shown in Fig. 8) have been carried out to test the theory. In the experiment, the cable length can be shortened or lengthened by regulating the device in Fig. (9). The bearing position can be regulated by the bolt in the ring beam shown in Fig. (10). Experimental results show that the bar internal force can

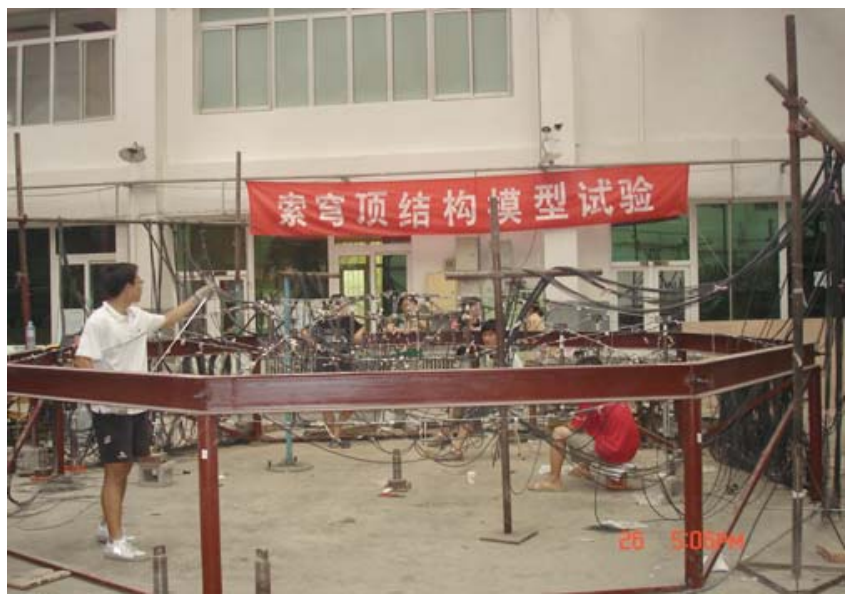

Fig. (8). Experimental model.

Table 6. Priority Sequence Table of Adjusted Member Bars

\begin{tabular}{|c|c|c|c|c|c|c|c|c|c|c|c|}
\hline Sequence & RC1 & RC2 & RC3 & DC1 & DC2 & DC3 & HC1 & HC2 & S1 & S2 & S3 \\
\hline \hline 1 & RC3 & HC2 & HC2 & DC1 & HC2 & HC2 & HC2 & HC2 & HC2 (-) & HC2 (-) & HC2 (-) \\
\hline 2 & RC1 & RC3 & RC3 & HC2 & RC3 & RC3 & RC3 & RC3 & RC3 (-) & RC3 (-) & RC3 (-) \\
\hline 3 & HC2 & RC2 & RC2 & RC3 & HC1 & DC3 & HC1 & DC3 & RC2 (-) & RC2 (-) & DC3 (-) \\
\hline 4 & RC2 & DC3 & DC2 & RC2 & DC2 & RC2 & DC2 & RC2 & DC1 (-) & HC1 (-) & RC2 (-) \\
\hline 5 & DC3 & RC1 & HC1 & DC3 & DC3 & HC1 & DC3 & HC1 & DC3 (-) & DC3 (-) & HC1 (-) \\
\hline 6 & HC1 & HC1 & DC2 & RC1 (-) & RC2 & DC2 & RC2 & DC2 & HC1 (-) & DC2 (-) & DC2 (-) \\
\hline 7 & DC2 & DC2 & RC1 & HC1 & RC1 & RC1 & RC1 & RC1 & DC2 (-) & RC1 (-) & RC1 (-) \\
\hline 8 & DC1 (-) & DC1 & DC1 & DC2 & DC1 & DC1 & DC1 & DC1 & S2 & DC1 (-) & DC1 (-) \\
\hline 9 & S3 (-) & S2 (-) & S2 (-) & S2 (-) & S2 (-) & S2 (-) & S2 (-) & S2 (-) & RC1 (-) & S2 & S3 \\
\hline 10 & S2 (-) & S3 (-) & S3 (-) & S3 & S3 (-) & S3 (-) & S3 (-) & S3 (-) & S1 & S3 & S2 \\
\hline 11 & S1 (-) & S1 (-) & S1 (-) & S1 (-) & S1 (-) & S1 (-) & S1 (-) & S1 (-) & S3 & S1 & S1 \\
\hline
\end{tabular}


approach to the design value after initial regulating in accordance with the priority sequence in the table. After regulating twice, the deviation between actual internal force and design value can be controlled within $10 \%$.

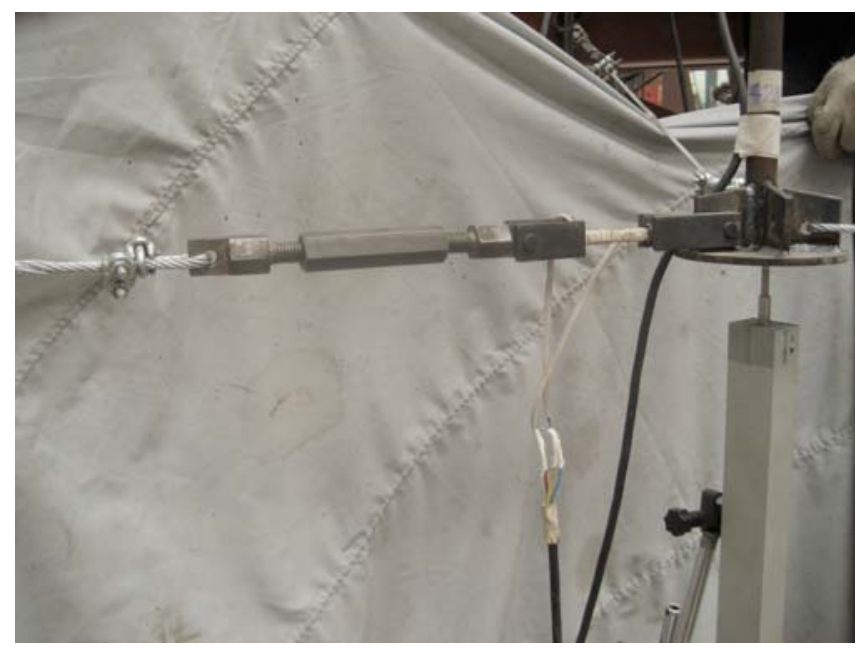

Fig. (9). Connection used to regulate cable length.

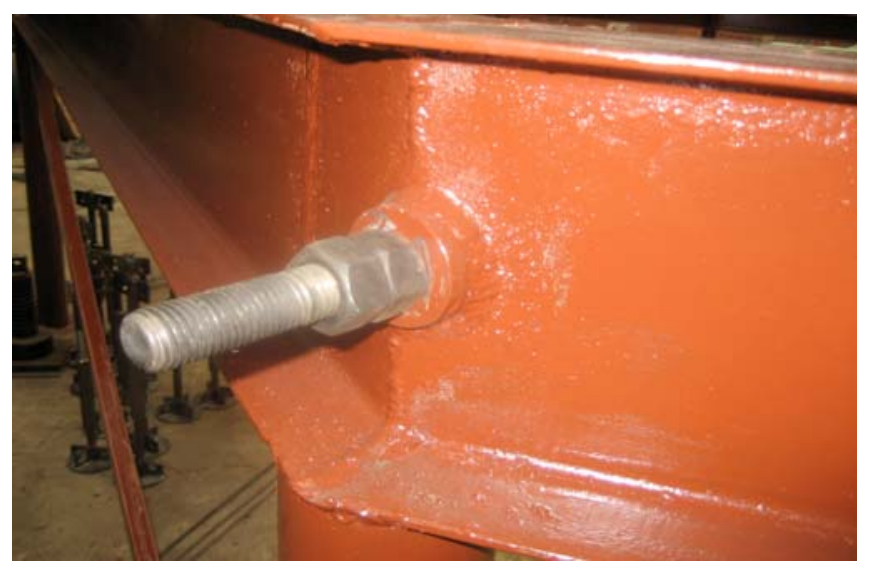

Fig. (10). connection used to regulate bearing.

\section{CONCLUSIONS}

Manufacture errors analysis for cable dome are carried out using sensitivity analysis method based on spearman rank-order correlation. Numerical results demonstrate that the sensitivity effect of radial bearing manufacture error on structural performance is most significant and should be controlled strictly. It is advised to control within 1/2000 of distance between adjacent supports for the span within $60 \mathrm{~m}$. Numerical results show that manufacture errors in $\mathrm{HC} 2$, RC3, DC3 and HC1 should be strictly controlled. For a cable with length of 10 to $30 \mathrm{~m}$, the maximum errors of $\mathrm{HC} 2, \mathrm{RC} 3$, DC3 and $\mathrm{HC} 1$ are advised to control in $0.05 \%$ of cable length, RC2 and DC2 are controlled in $0.10 \%$, and RC1 and DC1 in $0.15 \%$.

Aimed at cables in different position, effective regulating sequences are presented. It is advised to regulate the top four bars in priority sequence. The experiment has tested high regulating efficiency in accordance with the priority sequence mentioned in this paper.

\section{ACKNOWLEDGMENTS}

This research is financially supported by the Fundamental Research Funds for the Central Universities (Grant No.HEUCF100208), Harbin Special Study Fund for technological innovation (Grant No.2009RFQXG073)

\section{REFERENCES}

[1] R. B. Fuller, “Tensile-integrity structures”, U. S. Patent 3063521, December 13, 1962.

[2] D. H. Geiger, “Geiger roof structure”, U. S. Patent 4736553, April $12,1988$.

[3] D. H. Geiger, "The design and construction of two cable domes for the Korean Olympics", In: Proceedings of IASS-ASCE International Symposium on Shells, Membranes and Space Frames, 1986, pp. 265-272.

[4] M. P. Levy, "The Georgia Dome and beyond achieving lightweight-long span structure", In: Proceedings, IASS-ASCE International Symposium, 1994, pp. 560-562.

[5] H. Deng and S.L. Dong, "Analytical method of pretensioned reticulated structure", Journal of Zhejiang Univeristy, vol. 32, pp.42-47, September 1998 (in Chinese).

[6] J.H. Zhang and Y.G. Zhang, "Construction process analysis of Cable Dome", Journal of Wuhan University of Technology, vol. 30, pp.91-94, April 2008 (in Chinese).

[7] Tang J.M. Tang and Z.Y. Shen, "The Research of computation method of construction process simulation for axial symmetric Cable Domes with circular plane", China Civil Engineering Journal, vol. 31, pp.24-32, October 1998 (in Chinese).

[8] X.F. Yuan, S.L. Dong, "Inverse analysis of construction process of cable dome", Journal of Building Structures, vol. 22, pp. 74-78. April 2001 (in Chinese).

[9] D.B. Yang, Y.G. Zhang and J.Z. Wu, "Sensitivity analysis based on ANSYS and its application to single layer reticulated shell". World Earthquake Engineering, vol. 25, pp. 87-91, December 2009 (in Chinese).

[10] L.M. Zhang, W.J. Chen and S.L. Dong, "Manufactures errors and its effects on the initial prestress of Geiger cable domes", In: Proceeding of IASS-APCS, 2006, pp.16-20.

[11] JGJ 61-2003, "Technical Specification for Latticed Shells": PRC industry standard, China Architecture \& Building Press, 2003 (in Chinese).

(C) Zhang et al.; Licensee Bentham Open.

This is an open access article licensed under the terms of the Creative Commons Attribution Non-Commercial License (http://creativecommons.org/licenses/_by-nc/3.0/) which permits unrestricted, non-commercial use, distribution and reproduction in any medium, provided the work is properly cited. 